\title{
Quality of Life and Burnout among University Students
}

\author{
Gian Sugiana Sugara $^{1,2, *}$, Cece Rakhmat ${ }^{1}$, Juntika Nurihsan $^{1}$, Ilfiandra $^{1}$ \\ ${ }^{1}$ Department of Educational Psychology and Guidance, Universitas Pendidikan Indonesia, Indonesia \\ ${ }^{2}$ Department of Guidance and Counseling, Universitas Muhammadiyah Tasikmalaya, Indonesia
}

Received May 14, 2020; Revised June 27, 2020; Accepted July 20, 2020

Copyright $(2020$ by authors, all rights reserved. Authors agree that this article remains permanently open access under the terms of the Creative Commons Attribution License 4.0 International License

\begin{abstract}
The purpose of this study is to find a general picture of quality of life in students and to find the relationship between quality of life and burnout. Quality of life of students explains the level of satisfaction of student life and is a predictor of academic success. This relates to evaluating the satisfaction of life domains (health, self-esteem, spiritual, money or standards of living, work, play, helping, friendship, sibling relationships, spiritual, learning, creativity, family, neighborhood and community). Burnout is defined as a condition where individuals experience emotional exhaustion, depersonalization and reduce self-efficacy. The study used a cross-sectional design with a sample of 469 students. Data was collected using Quality of Life Inventory and Student Burnout Scale. Data analysis techniques used the Pearson correlation method to determine the relationship between quality of life and burnout among students. The F-Test technique is used to compare differences in quality of life based on gender. The results showed no significant difference in the quality of life of men and women. The highest life domain is family. While the lowest life domain is love, the relationship between quality of life and burnout was found to be negatively correlated. The burnout dimension consisting of emotional exhaustion, depersonalization and reducing academic efficacy was found to be negatively correlated with quality of life, based on the results of the study needed for the development of counseling interventions to improve the quality of life to reduce burnout in students.
\end{abstract}

Keywords Quality of Life, Burnout, Students, Correlation Research

\section{Introduction}

Life satisfaction is an influential indicator of psychological well-being and has been defined as a cognitive assessment of life as a whole (Diener, 1994).
People assess how important and how satisfied with life domains such as school, health, self-esteem, recreation, finance and so on. Frish (2013) explains that quality of life can be conceptualized as an evaluation of individual well-being towards life as a whole. The research findings of Thomas, McGrath \& Skilbeck (2012) explained that life satisfaction had a significant positive correlation on quality of life. In other words, life satisfaction becomes a strong predictor for measuring well-being and quality of life. In student activities, the quality of life of students can predict success in studies (Sirgy, Grzeskowiak \& Rahtz, 2006). This is a strong fact that quality of life is the goal of the development of students in supporting academic success.

Quality of life is conceptualized as an individual evaluation of overall life including physical and mental health (Wong et al., 2001). The World Health Organization (WHO) defines the quality of life as an individual's perception of their position in life in the context of the culture and value systems in which they live and in relation to their goals, expectations, standards and concerns (WHOQoL, 1998). "The best way to live" or "good life" is a condition that describes the quality of life. This definition refers to excellence or goodness in aspects of life that go beyond mere livelihood, survival, and longevity. The concept focuses on the domain or areas of life that make life very pleasant, happy, and useful, such as meaningful work, self-realization and a good standard of living (Frisch, 2013).

Quality of life for students is synonymous with the ability to realize academic goals and get the best results during academic activities. Norouzi (2012) found that quality of life was positively correlated with achievement motivation. Students who have a good quality of life will further increase the motivation to excel in students. In line with the results of research by Frisch (1992) who found that quality of life can reduce depressive symptoms in college students. The same thing was also found based on research conducted by Toghyani et al, (2011) who found that quality of life can improve well-being in adolescent boys. In another setting, it was found that quality of life can 
improve well-being in clients who have chronic illnesses (Rodriguez et al., 2005; 2006; 2011). Studies conducted by Rodriguez found that quality of life can improve the well-being of individuals who have chronic illnesses and negatively correlate with depressive symptoms. Other findings also found that quality of life was negatively correlated with anxiety and depression (McAlinden \& Oei, 2006). Thus, the findings show that well-being is a predictor for individuals to achieve quality of life.

Many students are not successful, and the reason is that there are many psychological, institutional, social, and university background variables that affect their educational performance. Individuals suffering from psychological disorders have a low quality of life (Unalan et al., 2008). Research has found that quality of life is negatively correlated with anxiety, severe depression, and psychological stress in psychiatric inpatients, university counseling centers and non-clinical undergraduate populations (Frisch, 1994). Burnout is a big problem that hinders the study of student success (Hutami, Sugara, Arumsari \& Adiputra, 2020). The results showed that quality of life can improve positive performance in individuals and negatively correlated with academic stress (Lyndon et al, 2017). Students who experience burnout will feel a decrease in motivation and make students rarely or even often do not attend classes regularly and also have an impact on their assignments and academic grades. This study aims to see the correlation between quality of life and burnout in college students.

\section{Literature Review}

Quality of life is very closely related to well-being where this word cannot be separated because it has a conceptual connection. There are several terms related to the theme of quality of life, including happiness, a good life, well-being, and wellness. Conceptually, the definition of quality of life is related to happiness, life satisfaction and well-being. The concept of well-being can be seen by using two approaches namely hedonic and eudaimonic. Hedonic approach views well-being as a focus on increasing pleasure and happiness (Ryan \& Deci, 2001). The hedonic model is also known as subjective well-being which focuses on three main concepts, namely life satisfaction, the absence of negative feelings and increasing positive feelings (Diener, Emmons, Larsen, \& Griffin, 1985). Another approach in looking at well-being is the eudaimonic model which emphasizes well-being when individuals can reach their potential optimally and are able to realize them (Lent, 2004). In contrast to the hedonic model which focuses on increasing pleasure and happiness, the eudaimonic approach tends to focus on a large number of domains of life, although it varies significantly regarding the fundamental elements that determine well-being. For example, the eudaimonic model is a psychological well-being model from Ryff \&
Keyes (1995) which shows that well-being consists of six elements: self-acceptance, positive relationships with others, independence, environmental mastery, life goals and personal growth.

Another term that can be used in the conception of well-being is the "wellness" which is better known in the area of counseling studies. Some researchers use the term "wellness" interchangeably with the "well being" (Hattie, Myers, \& Sweeney, 2004; Harari, Waehler, \& Rogers, 2005). The term 'wellness' close to the eudaimonic approach focuses on the optimal functioning of the individual. Conceptually, 'wellness' is defined as a condition that is oriented towards maximizing the potential of an individual in order to be able to realize potential (Palombi, 1992). The conceptualization of "wellness" emphasizes that well-being is characterized by the absence of disturbances that impede him. Wellness is described as well-being holistically in the domain of life (Palombi, 1992; Hattie, Myers, \& Sweeney, 2004). Quality of life cannot be separated from the concept of well-being. Because these two concepts have similarities in understanding the concept of well-being. Quality of life can be defined as a condition in which the degree or level reaches the good life which can be sorted from high to low or an excellent life to the poor (Veenhoven, 1984). This concept focuses on the ability of individuals to carry out self-realization in achieving a happy and meaningful life (Frisch, 2013).

The World Health Organization (WHO) defines quality of life as an external and complex concept and is influenced by physical health, psychological state, level of independence, social relations and their relationship to their environmental characteristics (WHOQOL Group, 1998). When viewed from the hedonic and eudaimonic approaches, quality of life uses both concepts to measure well-being. This condition of achievement is also known as the functional ability of the potential of the individual or the achievement of the individual in self-realization. The concept of life satisfaction is a predictor of achieving well-being (Frisch et al., 1992; Diener et al., 1999). These findings indicate that life satisfaction is an important factor in measuring quality of life. While well-being is the ultimate goal achieved by individuals.

Frisch (2013) explains that quality of life is interpreted as an individual subjective evaluation of something important in self that is related to the fulfillment of needs, goals and expectations in the domain of individual life. For this reason, the construct of the quality of life theory developed in this study is defined as a subjective evaluation of well-being conditions based on individual satisfaction in the life domain that is important to the individual. The life domain measured 16 sub-scale consists of health, self-esteem, spiritual, money or standard of living, work, play, learning, creativity, helping or social services, love, friends and friendship, relationships with relatives, homes, neighborhoods and communities.

Burnout is considered as a defensive coping concept 
which is explained as a passive strategy in dealing with stressful situations. Schaufeli et.al. (2002) burnout among students was interpreted as feeling tired because of the demands of study, having a cynical attitude to what was learned and feeling inept to complete the study. Student Burnout is conceptualized into three parts: emotional exhaustion, depersonalization and decreased academic self-efficacy (Sugara, 2016). Emotional exhaustion is described as feeling too emotional and drained by others (Schaufeli \& Greenglass, 2001). Depersonalization is described as a negative or inappropriate attitude towards others, loss of idealism, and withdrawal (Maslach \& Leiter, 2016). The decline in academic beliefs refers to a decrease in feelings of competence and achievement of individual success with others (Schaufeli \& Greenglass, 2001).

Students who experience burnout will feel a strain, overwhelmed, and exhausted. This has an impact on student performance and decreasing productivity in learning. Cordes \& Dougherty (1993) found the burnout effect of students was characterized by low commitment in learning, higher fatigue, absenteeism, reduced productivity, morale, and lower human judgment. Maslach \& Leiter (2008) described the impact of burnout closely related to anxiety, depression, and sleep disorders. Casserley \& Megginson (2009) explained the effects of burnout causing physical and emotional fatigue that insomnia, weight gain, chronic fatigue, increased use of alcohol or drugs, and so forth. The negative effect of burnout on student's causes procrastination behavior and even including suicidal thoughts (Dyrbye, et al., 2008). The effect of burnout on students is assumed to affect performance and quality of life. This is because the level of burnout that is not able to be managed imposes a feeling of inferiority and feeling incompetent (Schaufeli \& Greenglass, 2001). The hypothesis of quality of life and burnout explains that the higher the quality of life, the lower the level of burnout of students. Thus, the study aims to find a correlation between quality of life and burnout of existing students.

\section{Method}

\subsection{Participants}

The study used a cross-sectional design with a sample of 469 students from the Universitas Muhammadiyah Tasikmalaya consisting of 333 women and 136 men. Data was collected through the Quality of Life Inventory and Student Burnout Scale. Additional data used a questionnaire that revealed student demographic data consisting of age, gender and study program.

\subsection{Procedure}

The research uses two instruments: Quality of Life
Inventory is used to measure the level of life satisfaction and Student Burnout Scale measures the level of students' burnout. Quality of Life Inventory and Student Burnout Scale are given randomly to students in classrooms on scheduled courses. Participants were asked to be willing to volunteer to fill out the two instruments. The researcher explains the purpose of the research and maintains the confidentiality of the participants.

\subsection{Measures}

\section{Quality of Life Inventory (Frisch, 1994)}

QOLI.is a measuring tool to reveal the quality of life. QOLI measures 16 domains of life: health, self-esteem, spiritual, money or standard of living, work, play, helping, friendship, sibling relationships, spiritual, learning, creativity, family, neighborhood and community. Respondents rated how important each of the 16 domains was for their overall happiness and satisfaction $(0=$ not at all important, $1=$ important, 2 = very important) followed by ranking how satisfied they were in the area $(=3=$ very not satisfied, $-2=$ dissatisfied, $-1=$ slightly satisfied, $+1=$ quite satisfied, $+2=$ satisfied, $+3=$ very satisfied). The score on the important and satisfying part for each item is multiplied to form a rating that is from -6 to 6 . Life satisfaction is the total score of the importance and satisfaction of each domain in the quality of life assessed by respondents. QOLI has shown to have good internal consistency, $a=0.79$; and reliability of retesting, $r=0.73$ for 2 weeks with standard deviation $(\mathrm{SD})=3.9$. The convergent and discriminant validity test shows that QOLI has a significant correlation with other subjective well-being measures. QOLI Has a positive correlation with the Quality of Life Index (Ferrans \& Power, 1985) where $r$ $=0.75, \mathrm{p}<0.001$. It has a negative correlation with the Depression Anxiety Stress Scale (Lovibond \& Lovibond, 1995).

\section{Student Burnout Scale (Sugara, 2016)}

SBS is a measurement tool to determine the condition of burnout in students. The burnout instrument contains 35 items covering aspects of emotional exhaustion, depersonalization, and decreased academic confidence. Participants were asked to respond to statement items according to what they felt using a Likert scale where 1 (never), 2 (sometimes), 3 (often), and 4 (always). SBS has demonstrated good instrument reliability using the Spearman-Brown split-half technique and obtained a level of internal reliability between $0.89-0.93$, which shows that the degree of instrument reliability is very high. This study shows that the burnout revealing instrument has well constructed validity.

\section{Results}

The results of the study are described in three parts. First, 
it presents the general distribution of quality of life and 16 domains of sub-scales to students. Second, the findings of differences in quality of life are generally associated with life domains based on sex. Third, showing the correlation between the total QOLI, 16 sub-scale domains were killed with burnout. The average age of students is 18.9 and elementary school $=1.63$. The youngest is 17 years old, and the oldest is 48 years old. The number of respondents was 469 students consisting of $71 \%$ women and $29 \%$ men. Judging from the place of residence during the study, there were $49.25 \%$ living together not with parents and $50.72 \%$ living with parents. The average monthly student expenditure is Rp. 900,000. Table 1 shows descriptive statistics of quality of life for students. The results showed a total QOLI with an average of 2.59 and a standard deviation of 1.41. From the 16 sub-scales of the QOLI domain, maximum scores were found in the Family domain $(\mathrm{M}=4.04 ; \mathrm{SD}=2.39)$ and minimum scores in the Love domain $(\mathrm{M}=1.13 ; \mathrm{SD}=2.31)$. Other findings show no significant difference in quality of life between students who live with parents and not with parents $(\mathrm{F}=1.724 ; \mathrm{p}=$ 0.345 ).

Table 2 shows descriptive statistics regarding differences in the quality of life profile of male and female students. The results showed no significant difference in the general quality of life profile between men $(\mathrm{M}=2.43$; $\mathrm{SD}=1.47)$ and women $(\mathrm{M}=2.67 ; \mathrm{SD}=1.36)$. The highest score of achievement in men is the domain of living self-esteem $(\mathrm{M}=3.35$; $\mathrm{SD}=2.48)$, while in women is the domain of family life $(4.23 ; \mathrm{SD}=2.29)$. Statistical analysis using the $\mathrm{F}$ Test shows that domains of significantly different quality of life are relative, spiritual and family. The research findings show female students have a significantly higher quality of life domain than male students in the relative domain $(\mathrm{F}=12.28 ; \mathrm{p}=0.001)$, spiritual $(\mathrm{F}=5.672 ; \mathrm{p}=0.018)$ and family $(\mathrm{F}=7.363 ; \mathrm{p}=$ 0.007). Other domains have no significant differences.

Table 1. Distribution of Quality of Life Domain in Student University

\begin{tabular}{|c|c|c|}
\hline Scale & Mean & Standard Deviation \\
\hline Total QOLI & 2.59 & 1.41 \\
Health & 2.87 & 2.71 \\
Self Esteem & 3.34 & 2.45 \\
Financial & 1.44 & 2.82 \\
Work & 1.75 & 2.32 \\
Home & 3.09 & 2.52 \\
Play & 1.79 & 2.41 \\
Helping & 2.15 & 2.41 \\
Love & 1.13 & 2.31 \\
Friends & 3.08 & 2.12 \\
Relative & 3.92 & 2.37 \\
Spiritual & 3.47 & 2.64 \\
Learning & 2.89 & 2.51 \\
Creativity & 2.34 & 2.47 \\
Family & 4.04 & 2.39 \\
Neighborhood & 2.00 & 2.10 \\
Community & 2.22 & 2.27 \\
\hline
\end{tabular}

Table 2. Distribution of Quality of Life Domain According to Gender

\begin{tabular}{|c|c|c|c|c|c|c|}
\hline \multirow{2}{*}{ Scale } & \multicolumn{2}{|c|}{ Male } & \multicolumn{2}{|c|}{ Female } & F & $p$ \\
\cline { 2 - 7 } & M & SD & M & SD & & \\
\hline Total QOLI & 2.43 & 1.47 & 2.67 & 1.38 & 2.642 & 0.105 \\
Health & 2.87 & 2.66 & 2.90 & 3.83 & 0.14 & 0.907 \\
Self Esteem & 3.35 & 2.48 & 3.34 & 2.42 & 0.004 & 0.989 \\
Financial & 1.08 & 2.95 & 1.62 & 2.75 & 2.947 & 0.087 \\
Work & 1.63 & 2.63 & 1.80 & 2.19 & 0.558 & 0.455 \\
Home & 3.03 & 2.43 & 3.12 & 2.56 & 0.117 & 0.733 \\
Play & 1.74 & 2.25 & 1.81 & 2.48 & 0.082 & 0.772 \\
Helping & 2.18 & 2.46 & 2.16 & 2.39 & 0.028 & 0.866 \\
Love & 1.42 & 2.47 & 1.01 & 2.24 & 3.046 & 0.082 \\
Friends & 2.90 & 2.33 & 3.15 & 2.02 & 1.302 & 0.255 \\
Relative & 3.32 & 2.72 & 4.16 & 2.17 & 12.28 & 0.001 \\
Spiritual & 3.01 & 2.89 & 3.65 & 2.51 & 5.672 & 0.018 \\
Learning & 2.67 & 2.52 & 2.98 & 2.49 & 1.509 & 0.220 \\
Creativity & 2.29 & 2.54 & 2.36 & 2.45 & 0.093 & 0.761 \\
Family & 2.57 & 2.58 & 4.23 & 2.29 & 7.363 & 0.007 \\
Neighborhood & 1.84 & 2.10 & 2.10 & 2.12 & 1.502 & 0.221 \\
Community & 2.21 & 2.31 & 2.26 & 2.27 & 0.051 & 0.822 \\
\hline
\end{tabular}


Table 3. Pearson correlation coefficients among men and women $(\mathrm{N}=469)$

\begin{tabular}{|c|c|c|c|c|c|c|c|c|c|c|c|c|c|c|c|c|}
\hline & Heal & Self & Fin & Wor & Hom & Play & Help & Lov & Fri & Rel & Spi & Lea & Cre & Fam & Neig & Com \\
\hline Health & - & & & & & & & & & & & & & & & \\
\hline Self-Esteem & $.377^{* *}$ & - & & & & & & & & & & & & & & \\
\hline Financial & $.254^{* *}$ & $.320^{* *}$ & - & & & & & & & & & & & & & \\
\hline Work & $.270^{* *}$ & $.318^{* *}$ & $.294^{* *}$ & - & & & & & & & & & & & & \\
\hline Home & $.274^{* *}$ & $.268^{* *}$ & $.200^{* *}$ & $.266^{* *}$ & - & & & & & & & & & & & \\
\hline Play & $.280^{* *}$ & $.251^{* *}$ & $.161^{* *}$ & $.226^{* *}$ & .072 & - & & & & & & & & & & \\
\hline Helping & $.249^{* *}$ & $.359^{* *}$ & $.255^{* *}$ & $.423^{* *}$ & $.235^{* *}$ & $.309^{* *}$ & - & & & & & & & & & \\
\hline Love & $.220^{* *}$ & $.246^{* *}$ & $.178^{* *}$ & $.219^{* *}$ & $.259^{* *}$ & $.154^{* *}$ & $.299^{* *}$ & - & & & & & & & & \\
\hline Friends & $.232^{* *}$ & $.316^{* *}$ & $.116^{*}$ & $.280^{* *}$ & $.318^{* *}$ & $.305^{* *}$ & $.424^{* *}$ & $.234^{* *}$ & - & & & & & & & \\
\hline Relative & $.289^{* *}$ & $.333^{* *}$ & $.169^{* *}$ & $.246^{* *}$ & $.224^{* *}$ & $.178^{* *}$ & $.209^{* *}$ & $.116^{*}$ & $.312^{* *}$ & - & & & & & & \\
\hline Spiritual & $.243^{* *}$ & $.270^{* *}$ & $.169^{* *}$ & $.289^{* *}$ & $.204^{* *}$ & $.164^{* *}$ & $.418^{* *}$ & $.199^{* *}$ & $.238^{* *}$ & $.320^{* *}$ & - & & & & & \\
\hline Learning & $.315^{* *}$ & $.322^{* *}$ & $.234^{* *}$ & $.371^{* *}$ & $.180^{* *}$ & $.332^{* *}$ & $.505^{* *}$ & $.279^{* *}$ & $.381^{* *}$ & $.260^{* *}$ & $.574^{* *}$ & - & & & & \\
\hline Creativity & $.282^{* *}$ & $.370^{* *}$ & $.273^{* *}$ & $.418^{* *}$ & $.272^{* *}$ & $.308^{* *}$ & $.405^{* *}$ & $.296^{* *}$ & $.381^{* *}$ & $.273^{* *}$ & $.513^{* *}$ & $.611^{* *}$ & - & & & \\
\hline Family & $.341^{* *}$ & $.257^{* *}$ & $.240^{* *}$ & $.243^{* *}$ & $.193^{* *}$ & $.244^{* *}$ & $.232^{* *}$ & $.143^{* *}$ & $.260^{* *}$ & $.570^{* *}$ & $.382^{* *}$ & $.346^{* *}$ & $.335^{* *}$ & - & & \\
\hline Neighborhood & $.301^{* *}$ & $.303^{* *}$ & $.296^{* *}$ & $.341^{* *}$ & $.270^{* *}$ & $.215^{* *}$ & $.369^{* *}$ & $.228^{* *}$ & $.313^{* *}$ & $.329^{* *}$ & $.360^{* *}$ & $.384^{* *}$ & $.401^{* *}$ & $.420^{* *}$ & - & \\
\hline Community & $.249^{* *}$ & $.337^{* *}$ & $.201^{* *}$ & $.353^{* *}$ & $.253^{* *}$ & $.163^{* *}$ & $.375^{* *}$ & $.225^{* *}$ & $.267^{* *}$ & $.264^{* *}$ & $.347^{* *}$ & $.318^{* *}$ & $.331^{* *}$ & $.370^{* *}$ & $.643^{* *}$ & - \\
\hline
\end{tabular}

Table 4. Correlation between of Quality of Life, Age, Total Burnout and Dimension of Burnout

\begin{tabular}{|c|c|c|c|c|c|}
\hline Sub-scale & Age & Total Burnout & Emotional Exhaustion & Depersonalization & Reduce Academic Efficacy \\
\hline Total QOLI & -0.03 & $-0.37^{* *}$ & $-0.36^{* *}$ & $-0.23^{* *}$ & $-0.27^{* *}$ \\
\hline Health & 0.06 & $-0.36^{* *}$ & $-0.44^{* *}$ & $-0.25^{*}$ & -0.17 \\
\hline Self Esteem & 0.202 & -0.18 & $-0.29^{*}$ & -0.12 & 0.01 \\
\hline Financial & 0.031 & -0.10 & 0.02 & -0.11 & -0.17 \\
\hline Work & 0.078 & -0.02 & -0.09 & 0.04 & -0.04 \\
\hline Home & -0.10 & -0.19 & -0.12 & -0.01 & -0.12 \\
\hline Play & -0.006 & -0.24 & $-0.30^{*}$ & -0.14 \\
\hline Helping & 0.099 & -0.16 & -0.12 & -0.15 & -0.13 \\
\hline Love & $0.33^{* *}$ & -0.20 & -0.15 & -0.23 & -0.06 \\
\hline Friends & -0.126 & -0.04 & -0.06 & 0.06 & -0.21 \\
\hline Relative & -0.025 & $-0.29 *$ & $-0.27 *$ & -0.21 & -0.17 \\
\hline Spritiual & -0.085 & -0.18 & -0.18 & -0.07 & -0.22 \\
\hline Learning & -0.095 & -0.24 & $-0.26 *$ & -0.07 & -0.09 \\
\hline Creativity & -0.059 & -0.20 & $-0.25^{*}$ & -0.09 & -0.23 \\
\hline Family & 0.015 & -0.24 & -0.18 & -0.16 & -0.06 \\
\hline Neighborhood & -0.023 & -0.16 & -0.19 & -0.13 & -0.10 \\
\hline Community & -0.133 & -0.10 & -0.02 & -0.16 & \\
\hline$*$ Correlation is significant at the 0.05 level (2-tailed). \\
$* *$ Correlation is significant at the 0.01 level $(2$-tailed).
\end{tabular}

Table 3 shows the correlations between the 16 scales between male and female combined samples because the difference between the correlation matrix in men and women is very minimal. Table 3 shows that all correlations between 16 QOLI sub-scales were significant $(\mathrm{P}<0.001)$ where a low correlation was found in the Love and Family domain $(r=0.143)$ and a high correlation was found in the Community and Neighborhood domain $(r=643)$.

Table 4 shows the correlation between quality of life, age and burnout. The first finding explains that there is no relationship between age, and 15 QOLI sub-scale domains except the Love domain which has a strong enough relationship. Second, there is a significant negative correlation between total QOLI and Burnout. This shows that the higher the level of burnout, the lower the quality of life. 2 of the 16 QOLI domains, health $(r=-0.36)$ and relative $(r=-0.29)$ had a significant negative correlation with Burnout. Other domains have no correlation. Third, a 
negative correlation was found between the total QOLI with Burnout dimensions: emotional exhaustion $(r=-0.36)$, depersonalization $(\mathrm{r}=-0.23)$ and reduce academic efficacy $(r=-0.27)$ with an adequate level of correlation. The emotional exhaustion found a negative correlation in the domain of quality of life: health, self-esteem, play, relative, learning and creativity (See table 4). Depersonalization obtained a negative correlation with the total QOLI and health domain. Reducing academic efficacy was found to have a negative correlation with total QOLI and home living domains.

\section{Discussion}

Quality of life is defined as an individual's evaluation of the conditions of well-being he experiences (Frisch, 1994). Individuals who achieve prosperity are characterized by satisfaction with self, social and ability to realize the potential. The results found that there were no differences in the quality of life for male and female students. Although the average score of quality of life of women is higher than men, it does not show statistically significant differences. This is consistent with the findings of Frisch's (1994) study that there were no differences in the quality of life for men and women in the United States. The same finding was also reported in studies of quality of life in Australian society, which explained there was no difference in quality of life based on gender (Thomas, McGrath \& Skilbeck, 2012). This can be explained by the absence of differences in well-being views between men and women. In accordance with the opinion of Diener (1994) quality of life is related to an individual's cognitive assessment of the conditions of satisfaction with life. Male and female students have no difference when making a conscious assessment of life satisfaction in general. This is supported by research findings that there is no significant difference in quality of life between students who live with parents and live not with parents. In contrast to the results of research that found the quality of life of Turkish students is influenced by residence (Unalan et al., 2008). Students living in sub-standard housing have a lower quality of life scores. The house features that are built to provide comfort that makes high social effects (Seeds \& Lloyd, 1997). Although these findings do not provide corroborating facts that there are differences based on gender, individual perceptions of the comfort of residence affect quality of life (Frisch, 1994).

Research findings show significant differences between men and women in the relative, spiritual and family domains. Women have higher life satisfaction in all three domains than men. This can be due to the expectation of the big role of women in society. Indonesian society has the belief that women are the foundation for the achievement of family well-being. That is, women have a strong role and function in achieving happiness and well-being. Thus, women's perceptions of quality of life in the relative, spiritual and family domains have different views from men. Women are more feminine, have good morals and politeness ethics in carrying out their roles. In the spiritual domain, it has a large role in the quality of life and has a positive correlation with improving quality of life and well-being (Abdel-Khalek, 2010). This is the reason students with high scores in the spiritual domain enjoy a better quality of life and have a high level of well-being.

These findings provide important conclusions that explain spiritual activity as a domain that has a positive impact on quality of life, positive mental health and well-being (Frisch, 1994; Abdel-Khalek, 2010). The relative and family domains in quality of life explain that women get higher scores than men. This can be explained because women tend to have an emotional attachment to extended family members. In accordance with the opinion of Johnson (2002) which explains attachment was first formed in the family. Every family member has an emotional bond because they feel accepted, loved and valued fully in the family environment. Conditions of positive attachment in the family have an impact on increasing family resilience (Sugara \& Rindanah, 2017).

Another finding from this study is that there is no correlation between age and the entire QOLI domain except the Love domain. Quality of life is not related to age because it is related to an individual's subjective view of satisfaction with the life they lead (Diener, 1994). Domain love is related to having satisfaction with the fabric of love. This relates to feeling loved, valued and cared for (Frisch, 1994). Domain of Love is part of emotions, so the more your age, the more mature you are in managing emotions. In accordance with the opinion of Sandtrock (2015) which explains that emotional maturity is characterized by the ability of individuals to manage emotions positively for personal growth. In the study of Skevington, Lofty, \& O'Connell (2004) it has been found that with increasing age, quality of life decreases but from adolescence to adulthood improvement in quality of life will increase. Students have been living in conditions that are felt to be easier such as easy to improve skills, have a higher income, and a pleasant environment can improve a more positive quality of life (Unalan et al, 2008).

Other findings of this study reported that quality of life had a negative correlation with burnout. In addition, burnout is negatively correlated with two of the 16 domains, namely the health and relative domains. This explains that the higher the quality of life, the lower the burnout level of students. Students who experience burnout often have an impact on health and relationships with others. Lyndon et al., (2017) research found a negative correlation between quality of life with burnout and has a positive correlation of the level of motivation to pretend to medical students. Quality of life is related to satisfaction, and burnout is related to dissatisfaction in academics. Schaufeli et. al (2002) explain the phenomenon of burnout among students 
referring to feel tired because of the demands of study, having a cynical and detached attitude towards one's studies, and feeling inept as a student. Students who experience burnout will feel stressed, overwhelmed, and exhausted (Hutami, Sugara, Arumsari \& Adiputra, 2020). This can affect the performance of students' performance and productivity in learning also decreases. Previous research has shown that burnout can lead to lower commitment, higher turnover, absenteeism, reduced productivity, low morale, and lower human judgment (Cordes \& Dougherty, 1993). Research conducted by Sugara (2018) found that most of the quality of life in college students is influenced by the academic culture of students and the campus environment.

Burnout is characterized by three dimensions: emotional exhaustion, depersonalization and reduce academic efficacy (Sugara, 2016). The results showed a negative correlation between total QOLI with the three dimensions of burnout consisting of emotional exhaustion, depersonalization and reduce academic efficacy. The dimension of emotional exhaustion is related to feeling too impassioned and being drained by others (Schaufeli \& Greenglass, 2001). Quality of life is related to the assessment of satisfaction with life. This is the opposite of emotional exhaustion, which explains the feeling of being tired and fatigued in life. This can be explained by the low ability of individuals to manage situations or pressures so that they consider themselves negative and have no expectations. Starch, Roberti \& Roth (2004) explains the condition of self-blame, cynical look at others and the future is often a predictor of students experiencing depression. Other findings also reported that there was a negative correlation between emotional exhaustion and the domain of health, self-esteem, play, relative, learning and creativity. Individuals who experience feeling fatigue tend to be dissatisfied with the life domain. The correlation explains individuals with emotional exhaustion are prone to experience depression and anxiety. This is in accordance with research Unalan et al., (2008) found a negative correlation between the level of state anxiety with physical health, psychological health, and independence but had a positive correlation found between the level of anxiety trait and physical / psychological health, social relations, the environment, and quality of life in general.

The depersonalization dimension is related to cynicism behavior in following learning activities. The research findings show that there is a negative correlation between depersonalization dimensions with total QOLI and the health domain of life. Sugara (2016) explains depersonalization related to avoidance behavior. Individuals exhibit the behavior of self-defense mechanisms against the academic demands and burdens they carry. Forms of cynical behavior that often arise in students who experience boredom of learning such as skipping college, not doing homework, or thinking negatively towards lecturers and losing interest in the subject. This can be caused by the low ability of individuals to face a challenge that is called resilience. Individual endurance in dealing with problems has a positive impact on the psychological health of individuals (Reivich \& Shatte, 2003). Depersonalization can also be related to the low ability of individuals to manage stress in carrying out academic activities (Maslach et al., 1996). This makes individuals have been negative coping with strategies by doing cynicism on study activities and often influences physical health.

Dimensions of reducing academic efficacy are related to referring to a decrease in a belief in an individual's ability to succeed in the study (Sugara, 2016). The results showed a negative correlation of dimensions of reducing academic efficacy with total QOLI and home living domains. Individuals consider themselves to be people who are unhappy and unfortunate, dissatisfied with the learning outcomes they get, feel incompetent, have low self-esteem and feel unachievable. The domain of home life is related to having satisfaction with the residence currently occupied. Self-efficacy is a psychological attribute associated with positive attitudes and behaviors to achieve goals. Bandura (1994) explains that self-confidence can be obtained, modified, enhanced or reduced through one or a combination of four sources, namely the experience of mastering something accomplishment, vicarious experience, social persuasion, and generation emotions (emotional / physiological states). Individual perceptions about satisfaction with the domain of home life have a close relationship with academic self-efficacy. An environment that supports study activities, a comfortable place to live is a factor related to quality of life (Seeds \& Lloyd, 1997). Thus, academic self-efficacy is a positive predictor for the improvement of quality of life for students. This can be explained because individuals who have high self-efficacy in the study have a good self-understanding of the potential and are able to realize it optimally.

\section{Conclusions}

In accordance with what was explained earlier, the purpose of this study was to determine the correlation between quality of life with a burnout in college students. Based on the results of the study found that there is a significant negative correlation between quality of life and burnout level. Viewed from the domain of quality of life, burnout has a negative correlation with the health and relative domains. Viewed from the burnout dimension, quality of life has a negative correlation with dimensions of emotional.exhaustion, depersonalization and reduces academic efficacy. Emotional exhaustion has a negative correlation with the life domain of health, self-esteem, play, relative, learning and creativity. Depersonalization has a negative correlation with the health domain of life. Reducing academic efficacy is negatively correlated with 
the domain of home life.

The facts of this study illustrate the phenomenon of burnout having a negative impact on improving the quality of life. As the previous findings from Lyndon et al., (2017) who reported burnout had a negative correlation with quality of life and achievement motivation in students. This implies the need for assistance services by college counselors to reduce burnout and improve quality of life. Counseling interventions to improve the quality of life becoming a preventive solution to the symptoms of burnout in students. Researchers need to study of the stages of change model as an initial part to help the process of changing the quality of life for students. For this reason, further research is focused on developing a model of counseling intervention based on a model of the stages of change in improving the quality of life of students.

\section{Acknowledgments}

The writers would like to express their gratitude to the Indonesian government especially the Indonesian Directorate General of Higher Education (DIKTI), Indonesia Endowment Fund for Education (LPDP) in funding this research and Indonesia University of Education (UPI) for permitting them to conduct development research in the education field.

\section{REFERENCES}

[1] Abdel-Khalek, A. M. (2010). Quality of life, subjective well-being, and religiosity in Muslim college students. Quality of life research, 19(8), 1133-1143.

[2] Bandura, A. (1994). Self-efficacy. In. VS Ramachaudran. Encyclopedia of human behavior, 4(4), 71-81.

[3] Casserley, T., \& Megginson, D. (2009). Learning from burnout: Developing sustainable leaders and avoiding career derailment. Routledge.

[4] Cordes, C. L., \& Dougherty, T. W. (1993). A review and an integration of research on job burnout. Academy of management review, 18(4), 621-656.

[5] Diener, E. (1994). Assessing subjective well-being: Progress and opportunities. Social indicators research, 31(2), $103-157$.

[6] Diener, E., Oishi, S., \& Lucas, R. E. (2003). Personality, culture, and subjective well-being: Emotional and cognitive evaluations of life. Annual review of psychology, 54(1), 403-425.

[7] Dyrbye, L. N., Thomas, M. R., Massie, F. S., Power, D. V., Eacker, A., Harper, W., ... \& Sloan, J. A. (2008). Burnout and suicidal ideation among US medical students. Annals of internal medicine, 149(5), 334-341.

[8] Ferrans, C. E., \& Powers, M. J. (1985). Quality of life index: Development and psychometric properties. Advances in
Nursing Science, 8 (1), 15-24.

[9] Frisch, M. B., Cornell, J., Villanueva, M., \& Retzlaff, P. J. (1992). Clinical validation of the quality of life inventory: A measure of life satisfaction for use in treatment planning and outcome assessment. Psychological Assessment, 4(1), 92101.

[10] Frisch, M. B. (1994). Quality of life inventory. Minneapolis, MN: National Computer Systems.

[11] Frisch, M. B. (2013). Evidence-based well-being/positive psychology assessment and intervention with quality of life therapy and coaching and the Quality of Life Inventory (QOLI). Social Indicators Research, 114(2), 193-227.

[12] Harari, M. J., Waehler, C. A., \& Rogers, J. R. (2005). An empirical investigation of a theoretically based measure of perceived wellness. Journal of Counseling Psychology, 52(1), 93.

[13] Hattie, J. A., Myers, J. E., \& Sweeney, T. J. (2004). A factor structure of wellness: Theory, assessment, analysis, and practice. Journal of Counseling \& Development, 82(3), 354-364.

[14] Hutami, N.R., Sugara, G.S., Arumsari, C., \& Adiputra, S. (2020). Hardiness Training Model to Reduce Burnout in College Student. International Journal of Scientific \& Technology Research, 9(3).

[15] Johnson, S. M. (2002). Emotionally focused couple therapy with trauma survivors. New York, NY: The Guilford Press.

[16] Lent, R. W. (2004). Toward a unifying theoretical and practical perspective on well-being and psychosocial adjustment. Journal of Counseling Psychology, 51(4), 482.

[17] Lovibond, P. F., \& Lovibond, S. H. (1995). The structure of negative emotional states: Comparison of the Depression Anxiety Stress Scales (DASS) with the Beck Depression and Anxiety Inventories. Behaviour research and therapy, 33(3), 335-343.

[18] Lyndon, M.P, Henning, M., Hussain, A., Khrisna, S., Zeng, I.,Yu, Tsu-Chieh \& Hill, R. (2017). Burnout, quality of life, motivation, and academic achievement among medical students: A person-oriented approach. Perspect Med Educ, 6(2): 108-114.

[19] Maslach, C., Jackson, S., \& Leiter, M. (1996). Burnout inventory manual. Palo Alto, CA: Consulting Psychologists.

[20] Maslach, C., \& Leiter, M. P. (2008). The truth about burnout: How organizations cause personal stress and what to do about it. John Wiley \& Sons.

[21] Maslach, C., \& Leiter, M. P. (2016). Understanding the burnout experience: recent research and its implications for psychiatry. World psychiatry, 15(2), 103-111.

[22] McAlinden, N. M., \& Oei, T. P. S. (2006). Validation of the quality of life inventory for patients with anxiety and depression. Comprehensive Psychiatry, 47, 307-314

[23] Norouzi, M. (2012). Relationship of quality of life and achievement motivation with under graduated student's anxiety. Open Access Scientific Reports, 1(1), 1-4.

[24] Palombi, B. J. (1992). Psychometric properties of wellness instruments. Journal of Counseling \& Development, 71(2), 
$221-225$.

[25] Reivich, K., \& Shatte, A. (2003). The resilience factor: 7 keys to finding your inner strength and overcoming life's hurdles. Harmony.

[26] Rodrigue, J. R., Baz, M. A., Widows, M. R., \& Ehlers, S. L. (2005). A randomized evaluation of Quality of Life Therapy with patients awaiting lung transplantation. American Journal of Transplantation, 5(10), 2425-2432.

[27] Rodrigue, J. R., Widows, M. R., \& Baz, M. A. (2006). Caregivers of patients awaiting lung transplantation: Do they benefit when the patient is receiving psychological services? Progress in Transplantation, 16, 336-342.

[28] Rodrigue, J. R., Mandelbrot, D. A., \& Pavlakis, M. (2011). A psychological intervention to improve quality of life and reduce psychological distress in adults awaiting kidney transplantation. Nephrology, Dialysis, Transplantation, 26(2), 709-715.

[29] Ryan, R. M., \& Deci, E. L. (2001). On happiness and human potentials: A review of research on hedonic and eudaimonic well-being. Annual review of psychology, 52(1), 141-166.

[30] Ryff, C. D., \& Keyes, C. L. M. (1995). The structure of psychological well-being revisited. Journal of personality and social psychology, 69(4), 719.

[31] Santrock, J. (2015). Essentials of life-span development. McGraw-Hill Higher Education.

[32] Schaufeli, W. B., \& Greenglass, E. R. (2001). Introduction to special issue on burnout and health. Psychology \& health, 16(5), 501-510.

[33] Schaufeli, W. B., Martinez, I. M., Pinto, A. M., Salanova, M., \& Bakker, A. B. (2002). Burnout and engagement in university students: A cross-national study. Journal of cross-cultural psychology, 33(5), 464-481.

[34] Schaufeli, W. B., \& Greenglass, E. R. (2001). Introduction to special issue on burnout and health. Psychology \& health, 16(5), 501-510.

[35] Seeds, P., \& Lloyd, G. (1997). Quality of life. London: Jessica Kingsley Publishers.

[36] Sirgy, M.J., Grzeskowiak, S. \& Rahtz, D. (2007), “Quality of college life (QCL) of students: developing and validating a measure of well-being”, Social Indicators Research, Vol.
80, pp. $343-60$

[37] Skevington, S. M., Lofty, M., \& O’Connell, K. A. (2004). The World Health Organization's WHOQOLBREF quality of life assessment: Psychometric properties and results of the international field trial. A report from the WHOQOL Group. Quality of Life Research, 13, 299-310.

[38] Storch, E. A., Roberti, J. W., \& Roth, D. A. (2004). Factor structure, concurrent validity, and internal consistency of the beck depression inventory - second edition in a sample of college students. Depression and anxiety, 19(3), 187-189.

[39] Sugara, G.S. (2016). Manual of Student Burnout Scale. Tasikmalaya: Department Guidance and Counseling UMTAS

[40] Sugara, G.S. \& Rindanah, R. (2017). Building Family Resilience - Emotion Focused Family Counseling Approach. In 1st International Conference on Educational Sciences Volume 2: ICES, ISBN 978-989-758-314-8, pages 57-62. DOI: $10.5220 / 0007045206060611$

[41] Sugara, G. S. (2018). Student Quality-of-Life in Academic Culture Perspective. JOMSIGN: Journal of Multicultural Studies in Guidance and Counseling, 2(1).

[42] Toghyani, M., Kalantari, M., Amiri, S., \& Molavi, H. (2011). The effectiveness of quality of life therapy on subjective well-being of male adolescents. Procedia-Social and Behavioral Sciences, 30, 1752-1757.

[43] Thomas, M.D., McGrath, A., \& Skilbeck, C.E. (2012). The psychometric properties of the quality of life inventory in an Australian community sample. Australian Journal of Psychology, 64(4), 225-234.

[44] Unalan, D., Celikten, M., Soyuer, F., \& Ozturk, A. (2008). Quality of life in Turkish university students and its relationship to levels of state-trait anxiety. Social Behavior and Personality: an international journal, 36(3), 417-424.

[45] Veenhoven, R. (1984). Conditions of happiness. Kluwer Academic, Dordrecht, Boston

[46] Wong, E., Cronin, L., Griffith, L., Irvine, E. J., \& Guyatt, G. H. (2001). Problems of HRQL assessment: How much is too much? Journal of Clinical Epidemiology, 54, 1081-1085.

[47] WHOQOL Group. (1998). The World Health Organization quality of life assessment (WHOQOL): Development and general psychometric properties. Social Science and Medicine, 46 (12), 1569-1585. 